Use of Landing Service and Parking Areas for Helicopter Emergency Medical Service (HEMS)

Hideki Honda; Takabisa Kawasbima; Nobuo Kaku

Department of Traumatology and Critical Care Medicine, Kurume University School of Medicine, Japan

Objectives: To identify whether service areas (SA) and parking areas (PA) would be available for landing spots for Helicopter Emergency Medical Service (HEMS) on the express highways of Kyusyu.

Methods: The landing spots were evaluated in the SA and PA from the point of geographically capable of functioning as heliports, and of allowing helicopters to land. The space of landing spot was needed over $40 \mathrm{~m}$ on each side.

Results: Of the 26 SA, all except one were rated as conditionally capable. Of the $46 \mathrm{PA}$, five (10.9\%) were rated "no problem"; five (10.9\%) were rated "conditionally capable"; $21(45.7 \%)$ as "conditionally difficult"; and $15(32.6 \%)$ were "impossible". It was revealed that 26 (56.5\%) could not be used in their present state. Some of PA are being repaired in regard to the landscape and the ability of drivers refresh themselves.

Conclusion: A system of transport for emergency patients should be established on the express highways. It is necessary that PA be repaired so as to also to be able to serve as heliports for the HEMS.

Keywords: emergency medical services (EMS); helicopter, highway; transport

Prehosp Disast Med 2002;17:s11.

\section{Medical Preparedness and Response: A Disaster Management Plan for Hospitals in India} Dr. Dolly Mathew

Indira Gandhi National Open University, New Delhi, India

Objectives: 1) To examine the disaster management operational plans of the hospitals in India, and to evaluate the role played by the hospitals vis-à-vis disasters, as in case of the Gujarat earthquake of 26 January, 2001; and 2) To suggest an effective disaster management plan to strengthen and expand the capacity, preparedness, and response of the hospitals to disasters.

Methods: Collection and analysis of data from the Department of Emergency Medical Relief of the Director General of Health Services, New Delhi; All India Institute of Medical Sciences, New Delhi; State hospitals in major cities, reports, data pertaining to Gujarat earthquake, and web-based information on the emergency management plans of other countries.

Results: Effective disaster management plans do not exist for the hospitals. The existing plans lack well-defined, standard operating mechanisms. Hence, a disaster management plan is laid down, which will enhance the preparedness and response of the hospitals, along with a strategy for the implementation and monitoring of the same.

Conclusion: An effective disaster management plan will enable the hospitals to meet devastating disasters like the one in Gujarat. The plan should be mandatory for all hospitals. It can serve as a blueprint for developing countries, especially of South Asia facing similar types of events and similar requirement for medical incident management.

Keywords: blueprint; disaster; disaster management; Gujarat, hospitals; India; plans

Prehosp Disast Med 2002;17:s11.

\section{Disaster Management in India: Current Initiatives Colonal Rajive Kobli \\ Centre for Disaster and Development, India}

Introduction: Periodically, various natural and humanmade disasters affect hundreds of thousands of lives in India. A disaster management planning exercise, at the national level on the behest of the Prime Minister, brought out the mechanism to be established.

Objective: To highlight the initiatives of the Government of India that have resulted in the development of bringing out the disaster management plan for the country.

Methods: Data collection and analysis from official reports, interviews of officials and members of High Power Committee, and perusal of documents.

Results: A national response plan, reports of five subgroups covering all types of disaster-specific reports on related issues, as related to India were developed. The outcome of strategy using an integrated approach to management of disasters was linked to the development process with stress on a culture of preparedness. The important activity was a series of consultations with government, non-government, and other organizations at all levels. Subgroups were formed on water and climate-related disasters, geological disasters, chemical, industrial and nuclear disasters, Accident-related disasters, and biological disasters. This work was done August 1999 through September 2001 , and now under active consideration.

The work included topics such as mapping missions, insurance, triggering mechanisms, knowledge network, community preparedness, media, and civil defense. Some of the research studies had been supported on retrofitting, role of local bodies, a national disaster information system, an early warning system, socio-psychological aspects, educational sector, agro-forestry, etc. All aspects are to be integrated into the plans at national, state, district; and community levels.

Conclusion: These efforts have assisted in understanding the effectiveness of disaster management planning for a large country with specific reference to India.

Keywords: data collection; disasters; disaster management; High Power Committee; India; National Response Plan

Prehosp Disast Med 2002;17:s11.

\section{Israeli Hospital Preparedness for Disasters}

LTC. G. Neuman; MAJ. I. Hendler, MAJ. M. Golan;

LTC. G. Margalit; MAJ. D. Naor;

MAJ. M. Pres, COL. B. Tadmor

Medical Department, Home Front Command (HFC), Israel Defense Force, Israel

Objectives: The Hospital Emergency Preparedness (HEP) 